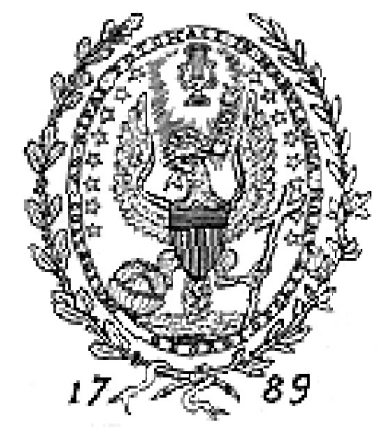

Bioethics Research Library

The Joseph and Rose Kennedy Institute of Ethics

Box 571212, Georgetown University

Washington, DC 20057-1212

202-687-3885; fax: 202-687-8089

bioethics@georgetown.edu

http://bioethics.georgetown.edu

\title{
Organizational Ethics and Health Care: Expanding Bioethics to the Institutional Arena
}

\author{
Laura Jane Bishop \\ M. Nichelle Cherry \\ Martina Darragh \\ Revised September, 1999
}

In 1995, the Joint Commission on Accreditation of Healthcare Organizations (JCAHO) expanded its patient rights standards to include requirements for assuring that hospital business practices would be ethical. Renamed "Patient Rights and Organization Ethics," these standards are based on the realization that a hospital's obligation to its patients is derived from two relationships: the patient-provider relationship governed by "clinical ethics," and the customer-supplier relationship governed by "business ethics." "[This] boundary between 'clinical' ethics and 'business' ethics is not clear and in many cases is nonexistent. While marketing and admission practices are seen as issues related to 'business' they can lead to unneeded admissions or demand for unneeded services, both of which can unnecessarily expose the patient to the risk of side effects or complications. Likewise, underutilization of needed services is likely to lead to less than optimal health outcomes" (I. Schyve 1996, p. 17). These new standards arose out of well-publicized concerns about abuses "...in which patients were admitted to hospitals unnecessarily and were discharged or transferred only after their insurance expired." (I. Schyve 1996, p. 15-16).

These abuses also sparked eloquent protests against threats to patient wellbeing and to the nature of the patient-provider relationship in the bioethics 
literature. The fiduciary responsibility of the provider to inform and to protect the patient was fragmented by insurer business practices such as gag clauses and economic credentialing of providers (VII. Scope Note $31,1996)$. The background role that the institution plays, though poorly articulated historically, has been brought sharply into focus by the explosive growth of the managed practice of medicine. The context of medical ethics is no longer limited to the resolution of individual cases, but instead encompasses the adoption of institutional structures to protect and promote patient welfare (IV. Emanuel 1995, p. 335). In this new configuration, the institution and the providers are co-fiduciaries for populations of patients, and the medicine that is practiced is "appropriately economically disciplined." The expression "My patient always comes first" is no longer "...intellectually serious or morally responsible." But, “... to be sure, both conceptually and in practice, being an economically disciplined fiduciary professional or institution is ethically unstable... The task is to identify the boundaries outside of which institutional policy and behavior will not count as an ethically defensible form of being...[a] fiduciary." (IV. McCullough 1998, pp. 143-44). This process of delimiting and enforcing boundaries requires the development of "....a language for talking about the ethical values of the organization. If such a language does not exist, discussions about ethics become cumbersome and unlikely to occur" (IV. Cleveland Clinic Foundation 1997, p. 2).

As with bioethics generally, the literature addressing organizational ethics is multidisciplinary. JCAHO's compliance guide for its revised standards, Ethical Issues and Patient Rights, draws on a wealth of ideas from both clinical ethics and business ethics. This is often an awkward alliance. "Because the study of organizational ethics is in its infancy compared to other areas of healthcare ethics, discussions about it often seem like hot air with no palpable payoff" (I. Boyle 1998, p. 2). The fact that “.... there is an ancient history that reflects widespread doubt about the moral probity of business" (II. Frederick 1995, p. 209) does not help. To begin, "Aristotle had rude things to say about business" (II. Jackson 1998, p. 401). A brief review of introductions to several of the business ethics textbooks cited in this bibliography reveals that a rebuttal of "business ethics as an oxymoron" is the standard opening paragraph. This stigma is unfounded, and "increased stability" has characterized the state of business ethics literature during the 1990s (II. Beauchamp and Bowie 1997, p. ix). Significant attention has been given to elaborating two often overlapping theories-stakeholder and social contractarian.

Originating in the 1960 s as a pun on "stockholder," proponents of stakeholder theory claim that a corporation's fiduciary responsibility extends beyond increasing its profitability to protecting the rights of individuals or groups affected by its actions. Popular as a strategic planning tool in the 1980 s, stakeholder theory has been "ethically resuscitated" in recent business literature to focus on ". . . a company's moral responsibilities to stockholders, employees, consumers, and local communities" (II. Frederick 1995, p. 227). Some view stakeholder theory as essentially flawed in that it gives rights to those in the community who may benefit from a company's success without requiring the corresponding responsibility to contribute to it (II. Ambler and Wilson 1995), while others critique its "masculine metaphors" with a feminist view of "...corporations as webs of relations among stakeholders," instead of as hierarchies of power and influence (II. Wicks et al. 1994, p. 475).

In addition to discussions of who counts as a participant in the delineation of corporate rights and responsibilities, social contractarians suggest that corporations become moral communities as all involved sketch the terms of their agreement. Borrowing from the political philosophy of Locke, Rousseau, and Hobbes, corporations are seen as engaging in an implied contract with society, and society is seen as having corresponding obligations to the corporations (VI. Donaldson 1982, pp. 39-41). Ultimately, “...[b]usiness ethics is about creating the right kind of community" (II. Hartman 1996, p. 7), and discussions from the business ethics literature of the moral status of the stakeholder and of the corporation inform the process of creating an ethical climate within a healthcare organization.

Drawing on the medical model of preventive medicine, the bioethics literature focuses on organizational ethics as "preventive ethics," with the health care ethics committee (HEC) functioning much as the primary care physician would in evaluating the institution's ethical well-being and recommending courses of action to remedy any deficits identified. "Until recently many HECs have considered economic issues to be outside their official purview" (V. Heitman and Bulger 1998, p. 153), but now the bioethics literature contains descriptions of HECs that have reconfigured themselves to address institutional issues (IV. Felder 1997; IV. Cassidy 1998; V. Pentz 1998). As HECs begin to explore their new role, individual hospitals and groups draft revised codes of ethics to include organizational ethics (III. Tavistock Group 1999; V. Lomax and Garthwaite 1997; IV. Crisp, et al. 1996). Unlike the "stable" business ethics literature, these articles describe works in progress, initial attempts at integrating institutional and clinical ethics.

The fact that HECs are engaged actively in creating an ethical climate and attending to co-fiduciary issues does 
not mitigate the importance of the individual in organizational ethics. While emphasizing that he believes "[g]reater emphasis on preventive action and education..." is warranted in addressing ethical issues in health care organizations, Van Rensselaer Potter asserts that "individuals bear the responsibility for what organizations do, at whatever cost, and with courage that is based on conviction as to what is right and just" (I. Potter 1996, p. 27).

The following annotations are arranged alphabetically by author within the following categories:

I. General Literature

II. Theoretical Issues

III. Codes of Ethics

IV. Implementing Ethics Programs

V. Role of Ethics Committees

VI. The Moral Status of the Corporation

VII. Selected Resources

\section{GENERAL LITERATURE}

Baum, Robert J., ed. Justice and the Health Care 'Industry'. Business \& Professional Ethics Journal 9(3 \& 4): 3-221, Fall/Winter 1990. [Special Issue]

The 16 papers in this special issue cover a broad range of topics and ethical problems that arise "at the interface of corporate practices and policies, governmental programs, and the health care industry" that together now define and provide health care services in the United States.

Bioethics Forum 12(2): 1-52, Summer 1996. Organizational Ethics. [Special Issue]

Articles on building an ethics infrastructure, on the interaction of market and clinical environments within hospitals, and on the opportunity for ethical growth presented by hospital mergers are included.

Boyle, Philip J. The Organizational Ethics Dilemma. Park Ridge Center Bulletin 3:2, February/March 1998. Wondering "[w]hat moral problems, if any, are unique or different for faith-based organizations," Boyle notes that "many of the ethical issues in organizations will be 'hidden in the woodwork,' refractory to moral analysis, [and] exciting to explore because they are so fresh in the ethics conversation and have such potentially significant consequences."

Bulger, Ruth Ellen, and Reiser, Stanley Joel, eds. Integrity in Health Care Institutions: Humane Environments for Teaching, Inquiry, and Healing. Iowa City: University of Iowa Press, 1990. 178 p. Physicians, hospital administrators, public health experts, philosophers, and bioethicists address the importance of an institutional ethic for academic health centers and the special challenges faced by such institutions in their efforts to articulate and maintain such an ethic.

Chryssides, George D., and Kaler, John H., ed. An Introduction to Business Ethics. London: Chapman \& Hall, 1993. 585 p.

Chryssides and Kaler provide an international approach to business ethics, but include significant material from the United States where much work in the field is carried out. Three chapters may be of special interest: corporations and responsibility (the nature of corporations, social responsibility, identity and accountability, and corporate governance); the greening of business (which includes a reading on Buddhist economics); and ethics and international business. The authors provide an introductory essay, a case study, and suggested discussion topics for each chapter.

Darr, Kurt. Ethics in Health Services Management. 3d ed. Baltimore: Health Professions Press, 1997. 310 p. Darr focuses on the development of organizational philosophies and mission statements, conflicts of interest, codes of ethics, organizational responses to ethical problems, fiduciary duties and responsibilities and organization/staff issues.

Gellhorn, Alfred. Institutional Ethics and Graduate Medical Education. New York State Journal of Medicine 85(10): 590-95, October 1985.

Gellhorn is concerned with the ethical responsibilities graduate medical colleges have to medical students, individual patients, their surrounding neighborhoods and communities, and society because of public funding of medical education and the ethical traditions of the medical profession. He argues that medical education must be expanded to accommodate and to equip graduates to fulfill the vision of physicians as leaders and social reformers able to "seek new solutions to the health problems of our times" and to participate actively in communities.

Khushf, George, ed. HEC Forum 10(2): 127-228, June 1998. Administrative and Organizational Ethics. [Special Issue]

Included in this issue are articles on conflicts arising at Catholic hospitals when contracting with Medicare managed care programs, on ethics committees for managed care administrators, and on a HEC developing a policy for resource allocation.

Henry, Christine, ed. Professional Ethics and Organisational Change in Education and Health. London: Edward Arnold, 1995. 144 p.

Henry provides an overview of business ethics for health care professionals and discusses such topics as 
the ethics of care and organizational change, and the implementation of an ethical values audit (EVA).

Olson, Linda. Ethical Climate in Health Care Organizations. International Nursing Review 42(3): 85-90, 95 May/June 1995.

Olson suggests that the notions of ethical climate and culture are important concepts for health care organizations and nursing ethics. She contrasts business ethics' focus on "how organizational variables impact on employee outcomes and behavior, and [on] unethical business practices," with nursing ethics' concerns "with the unique characteristics of the nurse-patient relationship... quality of care issues, life and death issues and access to resources," and issues related to "patients' rights, confidentiality, and privacy." Olson offers several strategies to support staff nurses while creating an ethical climate. In conclusion, she argues that research in both business and nursing ethics needs improved methodologies, research instruments, representative samples, and attention to both qualitative and quantitative measures.

Online Journal of Issues in Nursing, 31 December 1998. Topic 8: Administrative Ethics: What is Your Integrity Quotient (IQ)? Online at http://www.nursingworld.org/oijn/topic8/tpc8toc.htm [Special Issue]

This electronic journal issue contains five articles that provide an overview of organizational ethics in health care.

Potter, Van Rensselaer. Individuals Bear Responsibility. Bioethics Forum 12(2): 27-28, Summer 1996.

The author addresses the issue of whether an organization can "lead individuals to do good or evil," and "...assert[s] that individuals bear the responsibility for what organizations do."

Rodwin, Marc A. Medicine, Money \& Morals: Physicians' Conflicts of Interest. New York and Oxford: Oxford University Press, 1993. 411 p.

In this heavily referenced text, Rodwin includes a chapter on what needs to be done to hold physicians accountable for their fiduciary ideals. Finding disclosure and public intervention unsatisfactory, Rodwin suggests passage of legislative standards in tandem with adapting well-known processes to create the position of independent hospital auditor, the conflict-of-interest review board, and the regular practice of conflict-of-interest impact assessment.

Rovner, Julie. Organizational Ethics: It's Your Move. Health System Leader 5(1): 4-12, January 1998. Rovner discusses "...the growing movement toward the development of organizational ethics in healthcare. As providers are being increasingly confronted with conflicting demands-patients wanting the best possible care and purchasers asking for better use of finite resources-healthcare organizations are looking to ethics programs to help resolve these conflicts." In addition, the article outlines the Ethics Resource Center's four-part spectrum of organizational ethics and comprehensive business ethics.

Schyve, Paul M. Patient Rights and Organization Ethics: The Joint Commission Perspective. Bioethics Forum 12(2): 13-20, Summer 1996.

The author, a Joint Commission on Accreditation of Healthcare Organizations (JCAHO) executive, discusses the addition of standards on organizational ethics to its accreditation manuals, reviews the intent of these standards, and describes why ethics committees and consultation services have much to offer in negotiating " $[t]$ he boundary between "clinical ethics' and 'business ethics' [which] is not clear and in many cases is nonexistent."

Wear, Stephen. The Moral Significance of Institutional Integrity. Journal of Medicine and Philosophy 16(2): 225-30, April 1991.

Wear analyzes the 1986 court decisions requiring a religious hospital to permit Ms. Beverly Requena, a patient with advanced amyotrophic lateral sclerosis, to refuse artificial nutrition and hydration despite the hospital's objection that doing so would conflict with its moral commitments and religious heritage. Wear pointedly argues that we ignore the integrity of institutions at our peril. He is not persuaded that an institution's fiduciary responsibility to patients obligates it to provide care that it finds objectionable.

Wolf, Susan M. Health Care Reform and the Future of Physician Ethics. Hastings Center Report 24(2): 28-41, March/April 1994.

Wolf argues that some existing standards of physician ethics need to be clarified, and that other standards need to be changed. She makes a number of recommendations about the content of a new ethics for physicians and suggests guides for developing ethics for health care organizations.

Woodstock Theological Center Seminar in Business Ethics: Ethical Considerations in the Business Aspects of Health Care. Washington, DC: Georgetown University Press, 1995.39 p.

This pamphlet focuses on ethical dilemmas facing individual providers and executives of institutions. The pamphlet provides a list of principles and a checklist of questions that can be used to resolve ethical issues related to the business aspects of health 
care.

\section{THEORETICAL ISSUES}

Ambler, Tim and Wilson, Andrea. Problems of Stakeholder Theory. Business Ethics: A European Review 4(1): 30-35, January 1995.

Ambler and Wilson argue that the unresolved conflict between classical business theory (profits for shareholders) and neoclassical stakeholder theory (consideration of stakeholder interests and protection of their rights) leaves corporations struggling with the dilemma that recognizing and acknowledging stakeholder interests and developing socially conscious actions in the marketplace may dilute their ability to retain a clear vision and focused purpose. The authors assert that the main "...flaw [with stakeholder theory] lies in giving rights to those who may benefit from the company's success but neither contribute nor participate." They suggest a participant alternative that requires active involvement and recognizes rights and obligations to preserve the advantages of stakeholder theory while lessening its difficulties.

Beauchamp, Tom L, and Norman E. Bowie, eds. Ethical Theory and Business, 5th ed. Upper Saddle River, NJ: Prentice Hall, 1997. 661 p.

Beauchamp and Bowie provide an overview of ethical theory and business practice, offering discussion of fundamental concepts and problems, outlining normative ethical theories, and introducing the case method. Two foundational chapters follow on theories of corporate responsibility and different sources of business regulation. The remaining six chapters cover a variety of topics and contain relevant legal perspectives and case studies.

Donaldson, Thomas, and Werhane, Patricia H. Ethical Issues in Business: A Philosophical Approach, 6th ed. Upper Saddle River, NJ: Prentice Hall, 1999. 611 p. Well-known in the field of business ethics, Donaldson and Werhane have gathered papers written by classical and contemporary thinkers to address issues ranging from truth-telling and the virtuous manager to the moral responsibility of corporations and employee rights and responsibilities. The text also provides selections on traditional and modern discussions of property and profit, business values in the international setting, and contemporary business concerns, such as marketing, business strategy, and environmental issues.

Frederick, William C. The Business Ethics Question. In his: Values, Nature, and Culture in the American Corporation, pp. 209-44. New York: Oxford University
Press, 1995.

The author provides a comprehensive history of the development of three components of business ethics - the social contract theory, the stakeholder theory, and the behavioral/organizational ethics systems theory - and the areas where they intersect and overlap. Chapter sections focus on the "ethical resuscitation" of the stakeholder theory, especially in the work of Thomas Donaldson; Norman Bowie on the modern corporation as a moral community; and the notion of "ethical work climates," a "contextualist perspective that management theorists have proposed... [for] judging business behavior."

Hartman, Edwin. Organizational Ethics and the Good Life. New York: Oxford University Press, 1996. 214 p. Hartman suggests that "[b]usiness ethics is about creating the right kind of community, whether it is an organization or a community that comprises organizations" and that "...the community with which many of us identify most closely is constituted by the people who work in the organization that employs us." Using an Aristotelian approach, Hartman discusses the "good life" and the organization's role in promoting and creating the "good life."

Hummels, Harry. Organizing Ethics: A Stakeholder Debate. Journal of Business Ethics 17(13): 1403-19, October 1998.

Hummels "summarizes the development of the stakeholder oncept in the last decade" arguing that the managerial version of the stakeholder concept "does not pay sufficient respect to other interpretations of the concept." He "criticizes this dominant interpretation and argues for the need of an ongoing-academic and practical-debate on organizing and ethics."

Institutional Ethics: Finding Ethical Agreement Between Public Relations, Marketing, and Rationing. Hospital Ethics 6(1): 14-16, January/February 1990.

The journal editor summarizes the views of two American Hospital Association representatives and an ethics consultant on the ethical aspects of three interactions between hospitals and communities: public relations, marketing, and rationing.

Jackson, Jennifer. Business Ethics, Overview. In: Encyclopedia of Applied Ethics, vol. 1, ed. Ruth Chadwick, pp. 397-411. San Diego, CA: Academic Press, 1998.

The author discusses different frameworks for analyzing business ethics, including stakeholder, contractarian, and neo-Aristotelian virtues-based theories, and suggests that these "radical critiques of business may be mistaken but insights may be gained 
through studying them."

Kaptein, Muel. Ethics Management: Auditing and Developing the Ethical Conduct of Organizations. Dordrecht; Boston: Kluwer Academic Publisher, 1998. $228 \mathrm{p}$.

Kaptein discusses three ethical questions: "[1.] Can a corporation bear moral responsibility as a whole? [2.] How far does a corporation's moral responsibility extend? [3.] Can a corporation's moral responsibility be managed?". These questions are discussed in three parts that focus on defining, auditing, and developing the ethical content of the corporate mission, stakeholder theory, and ethics management.

Lagsdon, Jeanne M., and Yuthas, Kristi. Corporate Social Performance, Stakeholder Orientation, and Organizational Moral Development. Journal of Business Ethics 16(12-13): 1213-26, September 1997.

The authors review current literature on the application of Kohlberg's theory of individual moral development to organizations and suggest that a corporation can reach new stages of moral development by addressing the needs and social conditions of its stakeholders.

Potter, Robert Lyman. From Clinical Ethics to Organizational Ethics: The Second Stage of the Evolution of Bioethics. Bioethics Forum 12(2): 3-12, Summer 1996.

Potter discusses the need for a paradigm shift from patient-physician relationships to an "ecological paradigm in which the clinical encounter is understood in its larger context of the corporate system" as initially proposed by Van Rensselaer Potter.

Rie, Michael A. Defining the Limits of Institutional Moral Agency in Health Care: A Response to Kevin Wildes. Journal of Medicine and Philosophy 16(2): 221-24, April 1991.

Rie argues that the moral agency of institutions carries additional burdens and more stringent requirements that may not be discharged as easily as those associated with individual moral agency. $\mathrm{He}$ suggests that in a secular pluralist society, "institutions must hold a wide range of tolerance in the discharge of their mission as institutions serving the public" and may at times better discharge their moral views by ensuring that "the civil liberty of individuals is not transgressed by the application of institutional morality in health care."

Thomasma, David C. Promisekeeping: An Institutional Ethos for Healthcare Today. Frontiers of Health Services Management 13(2): 5-34, Winter
1996.

Thomasma is concerned with the changes wrought by managed care on the relationship between the physician and the patient, however, he states that managed care cannot be blamed for all the ills in health care. He suggests that the virtue of promisekeeping can guide managerial actions within health care by steering a middle course between "uncompromising principles and coarse self-interest."

Werhane, Patricia H., ed. Aspects of Health Care as a Business. Theoretical Medicine 11(4): 257- 324, December 1990. [Special Issue]

The articles in this collection explore a variety of issues raised by the increased commodification of health care, including the transformation of the physician's role and relationship with patients, the physician as medical entrepreneur and the concomitant potential for conflicts of interest, and the unsettling ramifications for health care of participation in the competitive market place. Several advantages of treating medicine as a business also are discussed.

White, Thomas I., ed. Business Ethics: A Philosophical Reader. New York: Macmillan Publishing Company, 1993. 867 p.

Chapters cover a broad range of areas, including, ethics and business; the morality of business and capitalism; justice; work and human well-being; corporate social responsibility; corporations; responsibility and personhood; employee rights and privacy; whistleblowing; sexual harassment; advertising; mergers and acquisitions; and business and the environment. White provides discussion questions, case studies, and additional readings for each topic.

Wicks, Andrew C.; Gilbert, Daniel R.; and Freeman, R. Edward. A Feminist Reinterpretation of the Stakeholder Concept. Business Ethics Quarterly 4(4): 475-97, October 1994.

The authors argue that stakeholder theory must be re-interpreted in light of feminist philosophy because moral insights into the responsibilities of corporations will thereby be enriched and freed from limiting traditions, and businesses will be permitted to be more responsive and adaptable.

Wildes, Kevin Wm. Institutional Identity, Integrity, and Conscience. Kennedy Institute of Ethics Journal 7(4): 413-19, December 1997.

Wildes argues that institutions and corporations can possess both integrity and conscience, and should seek to develop and articulate the moral identity essential to these moral faculties through a process of self-examination and evaluation. Wildes cites the 
struggle of Roman Catholic health care facilities to maintain an institutional identity and agency as a valuable model. He points to the fact that an institution's budget, strategic plan, planning process, and the moral commitments that shape the planning process and long-term goals, and the means used to achieve them, are a basis to evaluate the institution's commitment to its stated mission and vision. He suggests that hospital ethics committees evaluate the practice, policies, and moral culture of the institution and that the trustees and directors of an institution must take the lead on the broader questions of institutional identity and institutional life.

Wildes, Kevin W. Institutional Integrity: Approval, Toleration and Holy War or 'Always True to You in My Fashion.' Journal of Medicine and Philosophy 16(2): 211-20, April 1991.

Wildes focuses his attention at the level of health care institutions, arguing that the "moral identity and mission" of such institutions and their struggles to maintain moral commitments while delivering health care in a public, pluralistic context have often been neglected. Using religious hospitals as an illustration, Wildes suggests three responses open to institutions with particular moral commitments operating in the public domain. The development of public mission statements permits institutions to take a positive, proactive stance in the world, and allows for the possibility of compromise necessary to maintain identity.

\section{CODES OF ETHICS}

American College of Healthcare Executives [ACHE]. Code of Ethics. Chicago, IL: ACHE; 1995 August 22; 6 p. [Online]. Downloaded: http://www.ache.org/code/ html [15 March 1999].

This code sets standards of ethical behavior and outlines responsibilities for health care executives in their multiple professional relationships with members of their own organizations, other organizations, patients, clients, colleagues, the community, and society as a whole. The code states that health care executives function as "moral advocates" when fulfilling their obligations to those they serve. A grievance procedure and alternative actions that ethics committees may take are included as appendices.

American College of Physicians. Ethics Manual, 4th edition. Annals of Internal Medicine 128(7): 576-94, 1 April 1998.

Discussions of organizational ethics are included in the fourth edition of this code.
Catholic Health Association of the United States (CHA). Organizational Integrity in Catholic Healthcare Ministry: The Role of the Leader. St. Louis, MO: Catholic Health Association of the United States [CHA], no date; 14 p. [Online]. Downloaded: http://www.chausa.org/MISSSVCS/ETHICS/ORGET HIC/OETITLE.ASP [16 March 1999].

This online document provides a discussion of the Catholic world view of health care as a ministry and the implications of this view for leadership and decision making. The document is divided into three parts, and Part 3, "Organizational Integrity Operationalized," still evolving, provides a short list of issues relevant to organizational integrity.

Institutional Ethics: One Hospital's Attempt to Create an Institutional Code of Ethics. Hospital Ethics 11(2): 15-16, March/April 1995.

The journal editor presents the draft code of ethics developed by the ethics committee at the Riverside Health Group (RHG)/Riverside Hospital in Toledo, Ohio. The code sets out ethical standards of behavior that all employees and persons associated with RHG are expected to uphold and to promote, including: "...dealing honestly with internal and external clients, customers, suppliers, competitors, and financial partners; respecting patients' autonomy and their right to make informed decisions; seeking to serve the community and promoting fair reporting to the community [and] fair, just and effective use of available health care resources."

Kaptein, Muel, and Tempe, Johan. Twelve Gordian Knots When Developing an Organizational Code of Ethics. Journal of Business Ethics 17(8): 853-69, June 1988.

Kaptein and Tempe argue that codes, whether written or implicit, are important instruments to help increase the "moral resistance" of an organization-i.e., its ability to "resist influencing factors which exercise a downward pressure" on the organization's efforts "to fulfill its responsibilities with respect to its stakeholders." They identify four motivations for reconsidering an organization's moral code.

Ross, Judith, and Winger, Neil. Institutional Ethics: Hospital Practices and Policies for Denying Life-Sustaining Treatment. Whittier Law Review 15(1): 3349, 1994.

Ross and Winger discuss the fundamental assumptions and ethical commitments made by the UCLA hospital ethics committee in drafting the hospital's policy on medically appropriate aggressiveness of care, which states that patients and/or family members do not have the right to demand care identified as medically inappropriate, and establishes the terms of patient care offered at 
UCLA, as well as a process for conflict resolution.

Tavistock Group. A Shared Statement of Ethical Principles for Those Who Shape and Give Health Care. Annals of Internal Medicine 130(2): 144-47, 19 January 1999; and BMJ: British Medical Journal 318(7178): 249-51, 23 January 1999.

To address the changes in clinical practice precipitated by the managed practice of medicine, this group of health care providers, administrators, and organizations drafted a set of ethical principles to reflect the need to address institutional issues as well as clinical concerns. The five major principles are: (1) health care is a human right; (2) the care of individuals must be viewed and practiced within the context of patient populations; (3) the health care delivery system is responsible for preventing illness and mitigating the effects of disability; (4) cooperation among all health care providers and delivery systems is necessary; and (5) all parties share responsibility for quality improvement. The Group calls for comments and critiques.

Veterans Health Administration Ethics Center. A Model Organizational Code: Statement of Organizational Ethics. Lines, IL: Veterans Health Administration Ethics Center, no date; 5 p. [Online]. Downloaded: http://wrja1.hitchcock.org/oc.html [23 December 1998].

This statement prepared by the VA Hospital in Lines, Illinois, serves "as one model for those called upon to create such a document for their VA Facility." The statement includes sections outlining purpose, scope, policy, principles, employee practices and references.

\section{IMPLEMENTING PROGRAMS ETHICS}

American College of Healthcare Executives [ACHE]. Ethics Self-Assessment. Chicago, IL: ACHE, no date; 9 p. [Online]. Downloaded: http://www.ache.org/ ethicswb.html [1999 March 15].

The American College of Healthcare Executives designed this self-assessment questionnaire to help its members evaluate their own understanding of ethical obligations and assess their individual ethical behavior. A bibliography is provided.

Batts, Christy F. Making Ethics an Organizational Priority. Healthcare Forum Journal 41(1): 38-42, January/February 1998.

Batts provides an overview of the regulatory environment that has caused health care organizations to focus greater attention on ethical conduct in business practice. She also discusses the importance of health care organizations establishing an ethical compliance program and outlines ten key components that make such a program successful.

Cassidy, Judy. Calvary Hospital Focuses on Ethics: Integrating Clinical and Organizational Ethics Meets Needs of a Changing Healthcare System. Health Progress 79(6): 48-50, 52, November-December 1998.

Cassidy reports on the process by which Calvary Hospital has worked to ensure integration of clinical and organizational ethics. Calvary Hospital developed an organizational ethics statement and fields two on-call consult teams to respond to patient care and organizational ethical issues.

Catholic Health Association of the United States. $\boldsymbol{A}$ Workbook on Community Accountability in Integrated Delivery. St. Louis, MO: Catholic Health Association of the United States [CHA], 1995. 128 p.

This manual addresses issues that arise when a hospital mission statement incorporates community health care as part of its vision. Chapters focus on the development of public-private partnerships for sustainable program operations and community health insurance plans. The workbook also contains case studies of community projects undertaken by three Catholic hospitals.

Cleveland Clinic Foundation [CCF]. Department of Bioethics and the Ethics Committee. What Do They Mean By "Organizational Ethics"? Cleveland, OH: Cleveland Clinic Foundation [CCF], October 1997; 3 p. [Online]. Downloaded: http://www4.ccf.org/education/ bioethic/biocon8 .htm [2 February 1999].

This discussion provides an overview of some of the problems associated with the development of an ethical climate within an organization, which must go beyond the promulgation of an "ethics code," including structural constraints that may act as barriers to individual moral action. In recognition of these barriers, organizations need to develop ways to discuss the ethical values of an institution.

Crisp, Roger; Hope, Tony; and Ebbs, David. The Asbury Draft Policy on Ethical Use of Resources. BMJ: British Medical Journal 312(7045): 1528-31, 15 June 1996.

Although most writing in organizational ethics concerns the efforts of large health care institutions or systems to make decisions about institutional mission, values, and policies, this article presents a draft policy for the ethical use of resources in a general medical practice.

Emanuel, Ezekiel. Medical Ethics in the Era of Managed Care: The Need for Institutional Structures Instead of Principles for Individual Cases. Journal of Clinical Ethics 6(4): 335-38, Winter 
1995.

Emanuel exhorts medical ethicists to "... change our focus from articulating principles and rules that apply to individual cases to devising institutional structures that can ensure ethical behavior."

Ethics Resource Center [ERC]. The Organizational Ethics Committee: Roles and Responsibilities. Washington, DC: Ethics Resource Center [ERC], no date; 3 p. [Online]. Downloaded: http://www.ethics. org/erc/04-94d.html [15 March 1999].

This source outlines seven functions that should be addressed by an organization's ethics committee.

Felder, Michael. Bioethics and the HMO. HEC Forum 9(4): 355-364, December 1997.

Felder describes the establishment of the Community Health Plan Ethical Issues Committee (CHPEIC) and discusses its policy formulation and evaluation responsibilities.

Fletcher, James J.; Sorrell, Jeanne M.; and Silva, Mary Cipriano. Whistleblowing as a Failure of Organizational Ethics. Online Journal of Issues in Nursing, 31 December 1998. Topic 8: Administrative Ethics: What is Your Integrity Quotient (IQ)? Downloaded: http://www.nursingworld.org/oijn/topic8/ topic8_3.htm [19 March 1999].

The authors critique the JCAHO patient's rights standards as being limited to "policies and procedures that address the relationship between the use of services and financial incentives" and recommend the development of an "ethical climate" in an organization "to ensure that [an ethical] issue is addressed and that a satisfactory resolution is achieved."

Ham, Chris. Learning from the Tigers: Stakeholder Health Care. Lancet 347(9006): 951-53, 6 April 1996. Ham describes Singapore's stakeholder health care system, indicating that the most important lesson is that "....a stakeholder welfare system must grow out of a stakeholder economy rather than vice versa" if stakeholders are expected to take responsibility for their welfare.

Harwood, Sterling, ed. Business as Ethical and Business as Usual: Text, Readings, and Cases. Boston: Jones and Bartlett Publishers, 1996. 582 p.

Harwood organizes the 105 selections in this text around six challenges to the continuation of unethical business practices, namely, challenges from: ethical theory, culture, feminism, privacy, politics and economics, and the environment. Study questions are provided.

Joint Commission on Accreditation of Healthcare
Organizations. Ethical Issues and Patient Rights Across the Continuum of Care. Oakbrook Terrace, IL: The Commission, 1998. $156 \mathrm{p}$.

Developed to help hospitals comply with the JCAHO Rights and Ethics Standards, this handbook provides sample forms, checklists, policies, protocols, assessment tools, and guidelines.

McCullough, Laurence B. Preventive Ethics, Managed Practice, and the Hospital Ethics Committee as a Resource for Physician Executives. HEC Forum 10(2): 136-51, June 1998.

Drawing on lessons from the history of medicine, the author reviews the works of John Gregory (1723-1773) and Thomas Percival (1740-1803) on the economic aspects of physicians' fiduciary duties for patients and then discusses current law on informed consent as it applies to the responsibilities of managed care organizations to their patients.

Navran, Frank J. I Can't Do Anything. I'm Just A... The Individual's Role in Shaping Organizational Ethics. Washington, DC: Ethics Resource Center [ERC], no date; 5 p. [Online]. Downloaded: http://www.ethics.org/erc/07-92a.html [15 March 1999].

Every individual can make a difference in the ethical climate of an organization. The article suggests seven steps that an individual can take in order to shape an organization's ethical environment.

Reiser, Stanley Joel. The Era of the Patient: Using the Experience of Illness in Shaping the Missions of Health Care. JAMA: The Journal of the American Medical Association 269(8): 1012-17, 24 February 1993.

Reiser argues that to fulfill the missions of health care, health care practice, medical education and research, and institutional and general health care policy must focus on the value and authority of individual patients' symptoms, and the unique meanings they give to their illness experience. Reiser suggests that the formation of an education and policy committee and the implementation of monthly case rounds attended by consumer advisers and professional staff will be important steps to ensure the success and the integration and tracking of these efforts.

Reiser, Stanley Joel. The Ethical Life of Health Care Organizations. Hastings Center Report 24(6): 28-35, November/December 1994.

Reiser argues that thus far the efforts made by health care organizations to develop action-guiding codes of ethics and to identify organizational purposes and goals in mission statements have been too episodic and narrow to address complex issues in health care. 
He suggests the development of a basic commitments document and the use of administrative case rounds, and advocates for values-based staff education, and the cultivation of a humane institutional ethos.

\section{THE ROLE OF ETHICS COMMITTEES}

Heitman, Elizabeth, and Ruth Ellen Bulger. The Healthcare Ethics Committee in the Structural Transformation of Health Care: Administrative and Organizational Ethics in Changing Times. HEC Forum 10(2): 152-76, June 1998.

Three developments in the mid-1980s "established the trend against overtreatment and toward cost-containment, thus creating new incentives for undertreatment" and the necessity for healthcare ethics committee involvement in administrative and organizational ethics. Ethics committees can play a central role in the ethical evaluation of administrative and financial issues by facilitating discussion of these issues, ensuring that existing policies are clear and consistent, developing new policy guidelines, and serving as consultative resources.

Lomax, Karen J., and Garthwaite, Thomas L. VHA's Mission: Institutional Integrity, Non-Abandonment and VHA Special Emphasis Programs. HEC Forum 9(2): 182-93, June 1997.

Cognizant of generational ethics, the authors discuss sustaining costly special programs and safeguarding health care services for vulnerable groups in an era of fiscal constraints.

Nelson, William A., and Lomax, Karen J., eds. Veterans Administration HECs. HEC Forum 9(2): 109-96, June 1997. [Special Issue]

This issue reviews the Veterans' Health Administration's (VHA) efforts to maintain its institutional integrity and ethical commitments in the midst of a massive reorganization and the changing realities of the health care environment.

Nelson, William A., and Wlody, Ginger Schafer. The Evolving Role of Ethics Advisory Committees in VHA [Veterans Health Administration]. HEC Forum 9(2): 129-46, June 1997.

Nelson and Wlody's descriptions of the changing focus, role, structure, and membership standards that the Veterans' Health Administration (VHA) ethics advisory committees (EACs) now experience point to important trends for counterpart committees in other institutions and settings. A key change will be that EACs will be integrated into the overall mission and activities of medical facilities with ethical dimensions and responsibilities throughout the organization.
Pentz, Rebecca D. Expanding Into Organizational Ethics: The Experience of One Clinical Ethics Committee. HEC Forum 10(2): 213-221, June 1998. Pentz describes the migration of ethics committees from dealing with clinical ethics issues to organizational and/or institutional issues.

Weber, Leonard J. Taking on Organizational Ethics. Health Progress 78(3): 20-23, 32, May/June 1997.

In order to gain competence in analyzing and addressing organizational ethics issues, ethics committee members will need to educate themselves in the areas of "patient services, business and service plans, business and professional integrity, employee rights and responsibilities, and the organization's role in the community," as they once did in the area of clinical ethics.

\section{THE MORAL STATUS OF THE CORPORATION}

Curtler, Hugh, ed. Shame, Responsibility and the Corporation. New York: Haven Publications, 1986. $195 \mathrm{p}$.

These original essays by major contributors cover the range of thinking on the question of the moral status of the corporation. Curtler provides a very helpful introduction and overview of the text, a student summary and guide, and a glossary of terms.

Donaldson, Thomas. Corporations and Morality. Englewood Cliffs, NJ: Prentice Hall, 1982. 214 p. In answer to his own question "Can corporations be morally evaluated?," Donaldson discusses the moral status of corporations, business and social contract theory, notions of corporate responsibility, and employee rights.

French, Peter A. Collective and Corporate Responsibility. New York: Columbia University Press, 1984. $215 \mathrm{p}$.

French develops his well-known argument for corporate agency and corporate moral responsibility. Of particular interest is a short chapter applying his notion of collective responsibility to the medical profession, medical teams, and health care professionals in a variety of standard situations involving praise and blame.

French, Peter A. The Corporation as a Moral Person. American Philosophical Quarterly 16(3): 207-15, July 1979.

French concludes that "corporations can be fullfledged moral persons and have whatever privileges, rights and duties as are, in the normal course of affairs, accorded to moral persons," arguing that 
because organizations can act intentionally, they are moral persons. He relies on Corporate Internal Decision (CID) Structures to assign moral responsibility to corporations. This structure "accomplishes a subordination and synthesis of the intentions and acts of various biological persons into a corporate decision."

Goodpaster, Kenneth E. The Concept of Corporate Responsibility. Journal of Business Ethics 2(1): 1-22, February 1983.

Goodpaster treats the organization as an moral agent in society, "analogous to the individual while made up of individuals." He proposes a "principle of moral projection," which in its simplest terms "says that we can and should expect no more and no less of our institutions (taken as moral units) than we expect of ourselves (as individuals);" this principle permits the possibility of corporate responsibility.

Hartman, Edwin M. The Commons and the Moral Organization. Business Ethics Quarterly 4(3): 253-69, July 1994.

Hartman argues that organizations are a commons, a particular type of moral community. Robert C. Solomon and Patricia H. Werhane each reply to Hartman in papers published in the same issue.

May, Larry. The Morality of Groups: Collective Responsibility, Group-Based Harm, and Corporate Rights. Notre Dame, IN: University of Notre Dame Press, 1987. 200 p.

May argues that social groups have a moral status that is different from, although not entirely isolated from, the moral status of the individual persons who compose the groups. Because May conceives of social groups as "individuals in relationships," the group structure, or set of relationships that exist among the group's members are the basis for moral evaluation. After careful analysis, May asserts that "organized as well as unorganized groups can be said to act, to have intentions, and to be responsible for various harmful consequences." May ascribes rights to corporations but gives them lower standing than individual rights.

Nesteruk, Jeffrey. The Moral Status of the Corporation: Comments on an Inquiry. Business Ethics Quarterly 2(4): 461-63, October 1992.

Nesteruk praises Michael Phillips (see subsequent cite in this section) for drawing attention to an important and overlooked dimension of the discussion of corporate moral responsibility, i.e., the nature of corporations. However, Nesteruk argues that Phillips focuses on the descriptive aspects of the inquiry but ignores its normative aspects. Nesteruk emphasizes three normative dimensions of corporations.

Newton, Lisa H., and Pellegrino, Edmund D., eds. Collective Responsibility in Medicine. Journal of Medicine and Philosophy 7(1): 1-114, February 1982. [Special Issue]

These original essays are among the first to address the question of collective responsibility within the arena of medicine and health care. Pellegrino notes that the main ethical questions that haunt both medical and nonmedical collective decision making are the same: (1) how moral agency and responsibility should be allocated; (2) how "each member of a collective decision making group exerts his/her own moral agency"; and (3) when obligations conflict, to whom is moral responsibility primarily due? Other contributors discuss models of group choice and collective responsibility in medicine, nursing, and health care.

Ozar, David T. Do Corporations Have Moral Rights? Journal of Business Ethics 4(4): 277-81, August 1985. Unlike those who argue that corporations are incapable of moral agency, David Ozar, Peter French, and Michael Smith each separately have proposed what Ozar calls the "constitutive rules approach" to explain why corporate moral agency exists. This approach argues that a corporation should be thought of as a single moral agent for two reasons: (1) "a system of social rules exists which constitutes certain actions, performed by individual human persons, to be actions of the corporation as a single entity" and (2) such actions "include features sufficiently analogous to voluntariness and choice, as we find these in the actions of individual human persons" so that some of these actions may be described with justification as voluntary acts and products of corporate acts of choice. Ozar's constitutive rule theory here serves as a shorthand way to argue that corporations do not have moral rights because these entities exist and act only by convention.

Phillips, Michael J. Corporate Moral Personhood and Three Conceptions of the Corporation. Business Ethics Quarterly 2(4): 435-59, October 1992.

Phillips argues that to settle the issue of corporate moral responsibility the nature of corporations must be addressed. To that end, he describes three conceptions of corporations (concession, aggregate, and real entity) and explores their implications for ascription of corporate moral responsibility. He does observe, however, that satisfactory resolution of the question of moral responsibility may require the development of criteria tailored to corporations rather than relying on person-centered notions of responsibility. 
Ranken, Nani L. Corporations a Persons: Objections to Goodpaster's 'Principle of Moral Projection.' Journal of Business Ethics 6(8): 633-37, November 1987.

Ranken argues that only individual members of the corporation are relevant moral agents; "neither the corporation as an entity nor the organizational structure should be treated as having independent moral status." She charges that Kenneth Goodpaster's "principle of moral projection" or the analogy between corporations and individuals for purposes of moral description, moral analysis, and moral development is incorrect and dangerous and may distract from other more promising approaches to business ethics. Kenneth Goodpaster's response, "The Principle of Moral Projection: A Reply to Professor Ranken," is published in Journal of Business Ethics 6(4): 329-32, May 1987. (A publisher's error printed the reply before the original article.)

Sridhar, B. S., and Camburn, Artegal. Stages of Moral Development of Corporations. Journal of Business Ethics 12(9): 727-39, September 1993.

Sridhar and Camburn adopting a richer conceptualization of organizational systems than the standard open systems model allows. The open systems model views corporations and organizations simply as systems that "maintain themselves by sucking orderliness [and internal differentiation] from the external environment." As "symbol processing, culture producing and sharing entities, [corporations] are more akin to humans in their growth and development of cognition." Adapting Kohlberg's six stages of individual moral development to organizations, the authors propose parallels between the stages of moral development for individuals and those for organizational learning. They also create and test an "Organizational Response Analysis" instrument that permits empirical assessment of organizational behavior.

Velasquez, Manuel G. Why Corporations Are Not Morally Responsible for Anything They Do. Business \& Professional Ethics Journal 2(3): 1-18, Spring 1983.

Velasquez argues that French is wrong to say that corporations are morally responsible for their acts because "corporate acts do not originate in the corporation but in the corporation's members." According to Velasquez, corporations and corporate agents do not have the proper unity of body and mind to be said to act intentionally; therefore, corporations cannot be held morally responsible for their actions. Velasquez concludes that attribution of moral agency/moral responsibility to corporations is dangerous because it diverts us from correctly assigning blame and punishment to the individual persons who carried out the wrong action, and it tempts us to treat the corporation as a "larger-thanhuman-person whose ends and well-being are more important than those of its members."

Werhane, Patricia H. Persons, Rights, \& Corporations. Englewood Cliffs, N.J.: Prentice-Hall, 1985. 175 p.

After a general discussion of moral, political and economic rights, Werhane addresses the moral status of corporations and of employees, institutional moral agency, and the questions of corporate rights, responsibilities, and accountability. As secondary moral agents with a derivative capacity to make moral choices, corporations enjoy rights and responsibilities (broader than role-related obligations), and can be held accountable for their actions.

Wilson, Paul Eddy. Barring Corporations from the Moral Community-The Concept and the Cost. Journal of Social Philosophy 23(1): 74-88, Spring 1992.

Wilson argues that corporations are moral agents and aligns himself with Peter French's arguments for corporate responsibility. He discusses and contrasts analyses by theorists who adhere to methodological or moral individualism, thereby denying corporate moral agency and responsibility; those who hold that corporations are responsible societies although they are not persons or agents with goals or goods, a repudiation of methodological individualism; and those who award corporations goals or goods and moral responsibility but no metaphysical status as moral agents. Wilson argues that treating corporations as if they are not part of the moral community when they really are is disadvantageous particularly because it permits individuals within the corporations to be made scapegoats.

Wolgast, Elizabeth. Ethics of an Artificial Person: Lost Responsibility in Professions and Organizations (Stanford Series in Philosophy). Stanford, CA: Stanford University Press, 1992. $161 \mathrm{p}$.

Wolgast suggests that the concept of an "artificial" person originated by Thomas Hobbes has been so widely accepted that it is casually applied to the multitude of institutions that compose our modern society without concern for the grave moral implications of such arrangements. Wolgast argues that the practice of assigning artificial personhood to organizations threatens to undermine our understanding of moral responsibility and moral agency at all levels, even that of the individual person. Wolgast focuses on the unique difficulties raised by compound artificial agents, such as boards, councils, and corporations, particularly those 
accorded the legal status of persons.

\section{SELECTED RESOURCES}

BIOETHICSLINE $®$, prepared at the Kennedy Institute of Ethics under contract with the National Library of Medicine and with support from the National Human Genome Research Institute, covers the multi-disciplinary literature of bioethics. It is available free on the Internet vi a : http://bioethics.georgetown.edu. To retrieve additional citations on this topic simply enter:/*institutional ethics $(\mathrm{kw})$ in the "search for" box. Other searching aids can be found at: http://bioethics.georgetown.edu/bioline.htm

Other Internet resources include:

Ethics Resource Center: http://www.ethics.org/

Online Resources, The John F. Connelly Program in Business Ethics, School of Business, Georgetown University: http://www.gsb.georgetown.edu/prog/ connelly/resource.htm

Organizational Ethics and Health Policy, Joint Centre for Bioethics, University of Toronto: http://www.utoronto.ca/jcb/organizational_ethics.htm

Resources for Health Care Ethics Committees, Center for the Study of Bioethics, Medical College of
Wisconsin: http://www.mcw.edu/bioethics/ conference.html

Other print resources include:

Jones, Donald G., ed. A Bibliography of Business

Ethics, 1971-, Charlottesville: University Press of Virginia, 1977-.

Scope Note 31: Managed Health Care: New Ethical Issues for All. Kennedy Institute of Ethics Journal 6(2): 189-207, June 1996.

Fee-based online databases focusing on business literature that are available at many libraries include: $\mathrm{ABI} /$ Inform, Business and Industry, Business Periodicals Index, and LEXIS/NEXIS.

The authors thank George Brenkert, Ph.D., Director, John F. Connelly Program for Business Ethics, Georgetown University, and Kevin W. Wildes, S.J., Ph.D., Associate Director, Kennedy Institute of Ethics, Georgetown University, for their suggestions.

This Scope Note was prepared by Laura Jane Bishop, Ph.D., Research Associate, M. Nichelle Cherry, M.S.L.S., Research Assistant, and Martina Darragh, M.L.S., Reference Librarian at the National Reference Center for Bioethics Literature. 